Volume 3 Nomor 2 Desember 2021:47-54

\title{
KEANEKARAGAMAN JENIS TUMBUHAN BERBUNGA KELAS MAGNOLIOPSIDA DI PESISIR PANTAI KAPIHAK di PULAU SUMBA
}

\section{(Flowering plants diversity class of Magnoliopsida in the coast of Kapihak Beach in Sumba Island)}

\author{
Erlia Vany Roselince ${ }^{1}$ Yohana Makaborang ${ }^{1}$, Anita Tamu Ina ${ }^{1}$ \\ ${ }^{1}$ Program Studi Pendidikan Biologi Fakultas Keguruan dan Ilmu Pendidikan \\ Universitas Kristen Wira Wacana Sumba \\ E-mail : erlia.vany23@gmail.com
}

\begin{abstract}
The purpose of this study was to determine the diversity of flowering plants in the magnoliopsida class in the coast of Kapihak Beach. Sampling at the research site using purposive sampling technique. The method used in this study was the double plot method with observation plots measuring $20 \times 20 \mathrm{~m}$ for the tree phase, $10 \times 10 \mathrm{~m}$ for the shrub phase, $5 \times 5 \mathrm{~m}$ for the shrub phase and $2 \times 2 \mathrm{~m}$ for the herbaceous plant. The environmental factors measured were temperature, $p H$ and humidity. The results of the study found 17 orders, 22 families, 30 genera, 31 species and 537 individuals. The diversity index is classified as moderate with a value of $H=2,851$.
\end{abstract}

Keywords: Diversity, Flowering Plants, Kapihak Beach

\begin{abstract}
ABSTRAK
Penelitian ini untuk mengetahui keanekaragaman jenis tumbuhan berbunga kelas magnoliopsida di pesisir Pantai Kapihak. Pengambilan sampel tumbuhan pada lokasi penelitian menggunakan teknik purposive sampling. Metode yang digunakan dalam penelitian ini metode petak ganda dengan plot pengamatan berukuran $20 \times 20 \mathrm{~m}$ untuk fase pohon, $10 \times 10 \mathrm{~m}$ untuk fase perdu, $5 \times 5 \mathrm{~m}$ untuk fase semak dan 2 x 2 m untuk tumbuhan herba. Faktor lingkungan juga diukur meliputi, suhu udara, $\mathrm{pH}$ tanah dan kelembapan udara. Hasil penelitian ditemukan 17 ordo, 22 famili, 30 genus, 31 spesies dan 537 individu. Indeks keanekaragaman jenis tergolong sedang dengan nilai $\mathrm{H}=2,851$.
\end{abstract}

Kata kunci: Keanekaragaman, Tumbuhan Berbunga, Pantai Kapihak 


\section{PENDAHULUAN}

Tumbuhan berbunga disebut juga sebagai angiospermae yang memiliki ciri khas berupa bunga (Huda, dkk 2020:162). Tumbuhan berbunga diperkirakan mencapai $90 \%$ dari semua tipe tumbuhan yang tersebar luas di dunia (Huda, dkk 2020:163). Indonesia menempati peringkat pertama sebagai negara megadiversity ditinjau dari keanekaragaman jenis tumbuh-tumbuhan dan 25.000 tumbuhan berbunga tersebar di Indonesia (ICEL 2015:4). Hal ini didukung oleh penelitian Lembaga Ilmu Pengetahuan Indonesia (LIPI) dan World Wildlife Fund (WWF) Indonesia di kawasan Tesso Nilo-Riau (2006) menemukan 215 jenis tumbuhan berbunga dalam areal 0,2 ha. Selanjutnya LIPI dan Conservation International (CI) (2004) melaksanakan riset di kawasan Batang Gadis-Natal (Sumatera Utara) yang ternyata lebih kaya dari kawasan Tesso Nilo ialah 225 tipe tumbuhan berbunga pada kawasan hutan seluas 0,2 ha. Penelitian ini dapat menjadi bukti kekayaan alam hayati Indonesia beragam.

Pulau Sumba adalah pulau paling selatan Indonesia tepatnya di Nusa Tenggara Timur (BPS kabupaten Sumba Timur 2016). Pulau Sumba dikenal dengan keindahan alam seperti pantai. Daerah pantai adalah perbatasan antara ekosistem darat dan ekosistem laut yang dikenal dengan hutan pantai. Hutan pantai terbentuk dikarenakan adanya hempasan gelombang serta hembusan angin yang membuat pasir dari tepi laut membentuk gundukan ke arah darat (Tuheteru 2012:7). Pantai Kapihak merupakan salah satu pantai di Pulau Sumba tepatnya di Desa Mondu yang juga memiliki hutan pantai.

Berdasarkan hasil wawancara dengan Kepala Desa Mondu dan masyarakat pesisir, ada beberapa tumbuhan yang di manfaatkan seperti Spesies Ipomea pescaprae dimanfaatkan oleh masyarakat sebagai tali untuk mengikat kayu bakar sedangkan Caesalpinia bonduc dimanfaatkan sebagai obat herbal dan biji sebagai alat belajar
Volume 3 Nomor 2 Desember 2021:47-54 (menghitung) anak-anak di wilayah pantai sehingga keberadaannya berkurang. Permasalahan lain yang ditemukan yaitu kurangnya informasi mengenai tumbuhan di pesisir pantai setempat sehingga manfaat tumbuhan terabaikan yang berdampak pada kerusakan habitatnya. Selanjutnya aktivitas masyarakat yang mengambil tumbuhan Nyamplung (Calophyllum inophyllum) yang masih kecil untuk membuat pagar dan wilayah pesisir dijadikan wilayah pemukiman penduduk. Pemanfaatan secara terus-menerus tanpa memperhatikan kelestarian tumbuhan menyebabkan hilangnya kelestarian tumbuhan tersebut. Jenis-jenis tumbuhan tersebut tergolong dalam kelas magnoliopsida yang berperan dalam mencegah terjadinya abrasi pantai serta mampu menghambat kecepatan dan memecahkan tekanan angin menuju ke darat (Muanmar dkk, 2017:59).

Secara ekologis, tumbuhan berbunga berperan dalam keseimbangan ekosistem melalui simbiosis serangga ataupun mikroorganisme seperti sumber makanan, tempat perhentian ataupun fungsi ekologis lainnya (Kurniawati \& Martono, 2015:53). Selain serangga dan mikroorganisme, tumbuhan berbunga juga berperan penting dalam kehidupan manusia seperti tanaman obat, estetika lingkungan, peningkatan ekonomi dan untuk pemanfaatan pertanian (Huda dkk, 2020:164). Berdasarkan fungsi ekologis tersebut, dapat dikatakan tumbuhan berbunga merupakan salah satu pengendali kehidupan dan keberadaannya harus dilestarikan agar ekosistem tetap terjaga.

Melihat pentingnya peranan tumbuhan berbunga tersebut, maka perlu dilakukan penelitian tentang keanekaragaman Tumbuhan Berbunga Kelas Magnoliopsida di pesisir Pantai Kapihak.

\section{METODE PENELITIAN}

Penelitian ini merupakan penelitian deskriptifl dengan pendekatan kuantitatif. Penelitian ini dilakukan di Pantai Kapihak, 
Volume 3 Nomor 2 Desember 2021:47-54

Desa Mondu, Kecamatan kantang. Waktu pelaksanaan Desember 2020 - Januari 2021. Populasi dalam penelitian ini yakni seluruh tumbuhan berbunga (kelas magnoliopsida) yang terdapat di pesisir Pantai Kapihak, Desa Mondu, Kecamatan Kanatang. Sampel penelitian yaitu tumbuhan berbunga (kelas magnoliopsida) yang masuk dalam plot penelitian. Sampel diambil dengan teknik purposive sampling. Alat-alat yang digunakan berupa camera digital, alat tulis dan buku identifikasi, lembar pengamatan,meter, tali raffia, gunting, soil tester dan hydrometer. Bahan-bahan yang digunakan yakni tisu, kertas label, kapas dan alkohol $70 \%$. Penelitian menggunakan metode petak ganda dengan cara membuat plot pengamatan berukuran $20 \mathrm{~m}$ x $20 \mathrm{~m}$ untuk pohon, $10 \times 10 \mathrm{~m}$ perdu, $5 \times 5 \mathrm{~m}$ semak dan $2 \times 2 \mathrm{~m}$ tumbuhan herba pada setiap stasiun penelitian.

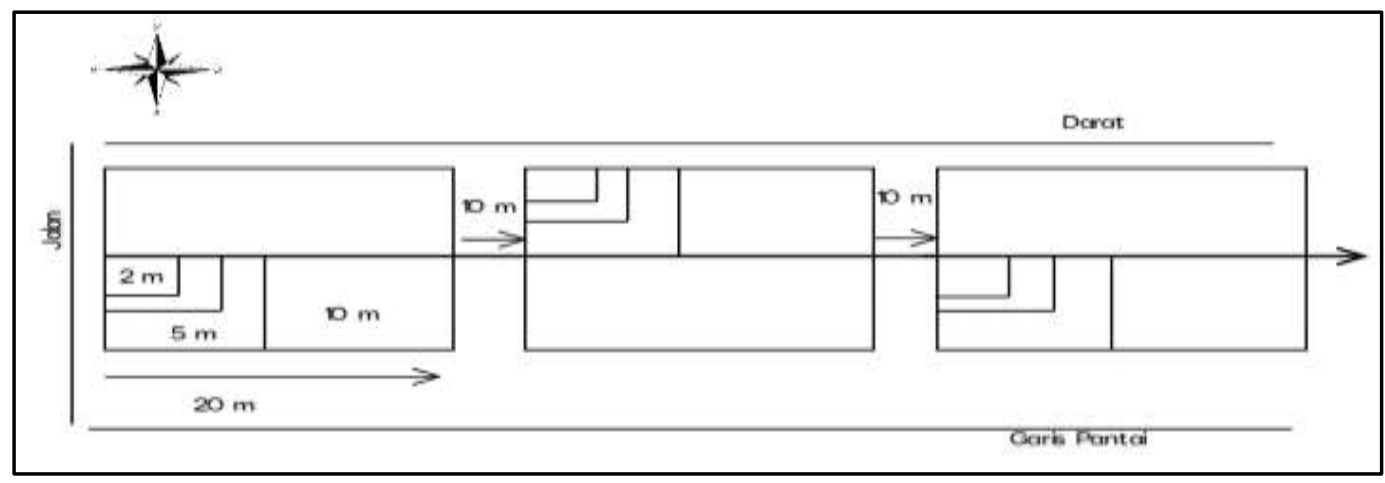

Gambar 1. Desain Metode Petak Ganda

Literatur yang digunakan untuk mengidentifikasi tumbuhan yaitu buku Taksonomi Tumbuhan (Spermatophyta) dari Tjitrosoepomo (2012), Flora dari Steenis, dkk (2013). Parameter faktor lingkungan pada lokasi penelitian juga dikur yaitu, suhu, $\mathrm{pH}$ tanah dan kelembapan.

\section{Indeks Nilai Penting}

Indeks Nilai Penting adalah parameter kuantitaif untuk menghitung dan mendeskripsikan tingkat dominansi spesies pada suatu komunitas tumbuhan, dengan rumus (Indriyanto, 2015).

\section{INP:KR+FR}

Keterangan:

INP: Indeks Nilai Penting

KR: Kerapatan Relatif

FR: Frekuensi Relatif

\section{Indeks Dominansi}

Indeks dominansi merupakan parameter untuk melihat tingkat terpusatnya penguasaan (dominan) spesies pada komunitas. Dominansi berkisar 0 sampai 1. Apabila mendekati 0, maka tidak adanya individu dominan sementara dominansi mendekati satu artinya ada satu spesies dominan (Odum 1993, dalam Kusumaningsari dkk, 2015: 60)

$$
\text { ID }=\Sigma(\mathbf{n . i} / \mathbf{N})^{2}
$$

Keterangan:

$$
\begin{aligned}
& \text { ID = indeks dominansi } \\
& n . \mathrm{i}=\text { nilai penting tiap spesies ke-i } \\
& \mathrm{N}=\text { total nilai penting }
\end{aligned}
$$

\section{Indeks Keanekaragaman Shannon- Wienner}

Indeks keanekaragaman merupakan parameter untuk memperkirakan keanekaragaman spesies salah satunya indeks Shannon.

$$
\hat{\mathbf{H}}=-\Sigma P i \operatorname{Ln} P \boldsymbol{i}
$$

Keterangan:

$\hat{\mathrm{H}}=$ indeks Shannon 
p.i $=$ ni $/ \mathrm{N}$, nilai penting dari setiap spesies

$\mathrm{N}=$ total nilai penting

\section{HASIL DAN PEMBAHASAN}

Volume 3 Nomor 2 Desember 2021:47-54

Hasil penelitian menunjukkan bahwa ditemukan sebanyak 31 jenis tumbuhan berbunga yang termasuk kedalam 17 ordo, 22 famili dan 30 genus, yang dapat dilihat pada Tabel 1.

Tabel 1. Jenis-jenis tumbuhan berbunga yang ditemukan di pesisir Pantai Kapihak

\begin{tabular}{|c|c|c|c|c|}
\hline No. & Nama Spesies & Suku & Habitus & Jumlah \\
\hline 1. & Acalypha ciliata $\mathrm{L}$. & Euphorbiaceae & Herba & 20 \\
\hline 2. & Chamaesyce hirta L. & Euphorbiaceae & Herba & 18 \\
\hline 3. & Spigelia anthelmia $\mathrm{L}$. & Loganiaceae & Herba & 34 \\
\hline 4. & Ageratum conyzoides $\mathrm{L}$. & Asteraceae & Herba & 16 \\
\hline 5. & Phyllanthus urinaria $\mathrm{L}$. & Phyllanthaceae & Herba & 34 \\
\hline 6. & Phyla nodiflora $\mathrm{L}$. & Verbenaceae & Herba & 6 \\
\hline 7. & Ipomea pescaprae $\mathrm{L}$. & Convolvulaceae & Herba & 28 \\
\hline 8. & Calotropis gigantea $\mathrm{L}$. & Asclepiadaceae & Herba & 8 \\
\hline 9. & Vitex trifolia $\mathrm{L}$. & Verbenaceae & Semak & 10 \\
\hline 10. & Jatropha gossypiifolia $\mathrm{L}$. & Euphorbiaceae & Semak & 56 \\
\hline 11. & Catharantus roseus L. & Apocynaceae & Perdu & 12 \\
\hline 12. & Lycopersicon escolentum Mill. & Solanaceae & Perdu & 2 \\
\hline 13. & Senna obtosifolia $\mathrm{L}$. & Fabaceae & Perdu & 6 \\
\hline 14. & Indigofera tinctoria Linn. & Fabaceae & Perdu & 12 \\
\hline 15. & Annona squamossa $\mathrm{L}$. & Annonaceae & Perdu & 8 \\
\hline 16. & Ziziphus mauritiana Lam. & Rhamnaceae & Perdu & 30 \\
\hline 17. & Leucaena leucocephala $\mathrm{L}$. & Fabaceae & Perdu & 42 \\
\hline 18. & Phyllanthus reticulatus Poir. & Phyllanthaceae & Perdu & 20 \\
\hline 19. & Caesalpinia bonduc L. & Fabaceae & Perdu & 4 \\
\hline 20. & Morinda citrifolia $\mathrm{L}$. & Rubiaceae & Perdu & 11 \\
\hline 21. & Moringa oleifera $\mathrm{L}$. & Moringaceae & Perdu & 2 \\
\hline 22. & Ficus Septica Burm F. & Moraceae & Perdu & 3 \\
\hline 23. & Justicia gendarussa Burm. F. & Acanthaceae & Perdu & 2 \\
\hline 24. & Terminalia catappa $\mathrm{L}$. & Combretaceae & Pohon & 32 \\
\hline 25. & Tamarindus indica $\mathrm{L}$. & Fabaceae & Pohon & 8 \\
\hline 26. & Ceiba pentandra $\mathrm{L}$. & Malvaceae & Pohon & 6 \\
\hline 27. & Prunus lauroceracus L. & Rosaceae & Pohon & 6 \\
\hline 28. & Thespesia polpunea $\mathrm{L}$. & Malvaceae & Pohon & 4 \\
\hline 29. & Schleichera oleosa $\mathrm{L}$. & Sapindaceae & Pohon & 2 \\
\hline 30. & Syzygiumm polyanthum Wight. & Mytaceae & Pohon & 1 \\
\hline 31. & Calophyllum inophyllum L. & Guttiferae & Pohon & 94 \\
\hline \multicolumn{4}{|c|}{ Total } & 537 \\
\hline
\end{tabular}

Kondisi lingkungan yang mencakup suhu, $\mathrm{pH}$ dan kelembapan sangat mempengaruhi kehidupan Tumbuhan Berbunga Kelas Magnoliopsida di Pesisir Pantai Kapihak. Data pengukuran disajikan pada Tabel 2. berikut. 
Volume 3 Nomor 2 Desember 2021:47-54

Tabel 2. Parameter faktor-faktor lingkungan di pesisir Pantai Kapihak

\begin{tabular}{llccc}
\hline No. Faktor lingkungan & \multicolumn{3}{c}{ Stasiun } \\
\cline { 3 - 5 } & & $\mathbf{1}$ & $\mathbf{2}$ & $\mathbf{3}$ \\
\hline 1. & Suhu & $30^{\circ} \mathrm{C}$ & $28^{\circ} \mathrm{C}$ & $30^{\circ} \mathrm{C}$ \\
& Hari-1 & $29^{\circ} \mathrm{C}$ & $28^{\circ} \mathrm{C}$ & $28^{\circ} \mathrm{C}$ \\
& Hari-2 & $30^{\circ} \mathrm{C}$ & $28^{\circ} \mathrm{C}$ & $31^{\circ} \mathrm{C}$ \\
& Hari-3 & & & \\
2. & pH & 7,0 & 7,0 & 7,0 \\
& Hari-1 & 7,0 & 7,0 & 7,0 \\
& Hari-2 & 7,0 & 7,0 & 7,0 \\
& Hari-3 & & & \\
3. & Kelembapan & $70 \%$ & $70 \%$ & $68 \%$ \\
& Hari-1 & $63 \%$ & $71 \%$ & $67 \%$ \\
& Hari-2 & $71 \%$ & $75 \%$ & $77 \%$ \\
\hline
\end{tabular}

Hasil pengukuran suhu pada hari pertama sampai hari ketiga rata-rata $29^{\circ} \mathrm{C}$ sedangkan hasil pengukuran $\mathrm{pH}$ yaitu 7,0 dan tidak mengalami perubahan, sementara hasil pengukuran kelembapan pada hari pertama hingga hari ketiga rata-rata $70 \%$

Tabel3. Indikator dan indeks ekologi

\begin{tabular}{|c|c|c|c|c|c|c|c|}
\hline No. & Nama Spesies & $\mathbf{K}$ & KR & $\mathbf{F}$ & FR & INP & ID \\
\hline 1. & Acalypha ciliate & 5,000 & $12 \%$ & 0,125 & $13 \%$ & 0,247 & 0,015 \\
\hline 2. & Chamaesyce hirta & 4,500 & $11 \%$ & 0,125 & $13 \%$ & 0,235 & 0,012 \\
\hline 3. & Spigelia anthelmia & 8,500 & $21 \%$ & 0,188 & $19 \%$ & 0,395 & 0,043 \\
\hline 4. & Ageratum conyzoides $L$ & 4,000 & $10 \%$ & 0,063 & $6 \%$ & 0,160 & 0,010 \\
\hline 5. & Phyllanthus urinaria & 8,500 & $21 \%$ & 0,188 & $19 \%$ & 0,395 & 0,043 \\
\hline 6. & Phyla nodiflora & 1,500 & $4 \%$ & 0,063 & $6 \%$ & 0,099 & 0,001 \\
\hline 7. & Ipomea pescaprae & 7,000 & $17 \%$ & 0,188 & $19 \%$ & 0,358 & 0,029 \\
\hline 8. & Calotropis gigantean & 2,000 & $5 \%$ & 0,063 & $6 \%$ & 0,111 & 0,002 \\
\hline 9. & Vitex trifolia & 0,400 & $15 \%$ & 0,500 & $50 \%$ & 0,652 & 0,023 \\
\hline 10. & Jatropha gossypiifolia & 2,240 & $85 \%$ & 1,00 & $67 \%$ & 1,348 & 0,720 \\
\hline 11. & Catharantus roseus & 0,120 & $8 \%$ & 0,095 & $10 \%$ & 0,159 & 0,006 \\
\hline 12. & Lycopersicon escolentum & 0,020 & $1 \%$ & 0,048 & $5 \%$ & 0,058 & 0,000 \\
\hline 13. & Senna obtosifolia & 0,060 & $4 \%$ & 0,048 & $5 \%$ & 0,080 & 0,002 \\
\hline 14. & Indigofera tinctoria & 0,120 & $8 \%$ & 0,095 & $10 \%$ & 0,159 & 0,006 \\
\hline 15. & Annona squamossa & 0,080 & $5 \%$ & 0,095 & $10 \%$ & 0,138 & 0,003 \\
\hline 16. & Ziziphus mauritiana & 0,300 & $19 \%$ & 0,143 & $14 \%$ & 0,303 & 0,038 \\
\hline 17. & Leucaena leucocephala & 0,420 & $27 \%$ & 0,143 & $14 \%$ & 0,544 & 0,074 \\
\hline 18. & Phyllanthus reticulates & 0,200 & $13 \%$ & 0,095 & $10 \%$ & 0,202 & 0,017 \\
\hline 19. & Caesalpinia bonduc & 0,040 & $3 \%$ & 0,048 & $5 \%$ & 0,069 & 0,001 \\
\hline 20. & Morinda citrifolia & 0,110 & $7 \%$ & 0,048 & $5 \%$ & 0,106 & 0,005 \\
\hline 21. & Moringa oleifera $L$. & 0,020 & $1 \%$ & 0,048 & $5 \%$ & 0,058 & 0,000 \\
\hline 22. & Ficus Septica & 0,030 & $2 \%$ & 0,048 & $5 \%$ & 0,064 & 0,000 \\
\hline 23. & Justicia gendarussa & 0,020 & $1 \%$ & 0,048 & $5 \%$ & 0,058 & 0,000 \\
\hline 24. & Terminalia catappa & 0,080 & $21 \%$ & 0,143 & $14 \%$ & 0,352 & 0,044 \\
\hline 25. & Tamarindus indica & 0,020 & $5 \%$ & 0,143 & $14 \%$ & 0,195 & 0,003 \\
\hline 26. & Ceiba pentandra & 0,015 & $4 \%$ & 0,143 & $14 \%$ & 0,182 & 0,002 \\
\hline 27. & Prunus lauroceracus & 0,015 & $4 \%$ & 0,143 & $14 \%$ & 0,182 & 0,002 \\
\hline 28. & Thespesia polpunea & 0,010 & $3 \%$ & 0,143 & $14 \%$ & 0,169 & 0,001 \\
\hline 29. & Schleichera oleosa & 0,005 & $1 \%$ & 0,071 & $7 \%$ & 0,085 & 0,000 \\
\hline 30. & Syzygiumm polyanthum & 0,003 & $1 \%$ & 0,071 & $7 \%$ & 0,078 & 0,000 \\
\hline 31. & Calophyllum inophyllum & 0,235 & $61 \%$ & 0,200 & $20 \%$ & 0,757 & 0,377 \\
\hline
\end{tabular}




\section{Indeks Nilai Penting}

Tumbuhan berbunga yang memiliki indeks nilai penting tinggi yaitu Jatropha gossypiifolia dengan nilai $1,348 \%$ sebanyak 56 individu sedangkan Lycopersicon escolentum dan Justicia gendarussa merupakan tumbuhan berbunga yang memiliki nilai penting rendah yaitu $0,061 \%$. Jatropha gossypiifolia, ditemukan dalam jumlah banyak karena berada pada kondisi lingkungan yang cocok untuk pertumbuhan sedangkan Lycopersicon escolentum dan Justicia gendarussa, ditemukan hanya pada satu stasiun.

\section{Indeks Dominansi}

Indeks dominansi pada lokasi penelitian tergolong tinggi yaitu 1,038. Indeks dominansi pada penelitian mencapai angka 1 artinya salah satu spesies memiliki indeks dominansi yang tinggi. Spesies yang mendominansi adalah, spesies ini tidak terdapat pada setiap stasiun tetapi hanya terdapat pada stasiun yaitu pada stasiun I dan stasiun III. Hal ini dikarenakan pada stasiun I dan stasiun III tempat terbuka yang terkena matahari dan substrat berbatu serta tumbuhan ini mudah beradaptasi dengan lingkungan tumbuhnya. Sejalan dengan Harianto (2017:2), Jatropha gossypiifolia adalah tanaman yang tumbuh secara liar dan di daerah terbuka yang terkena sinar matahari langsung maupun di pekarangan rumah. Syzygium polyanthum, merupakan indeks dominansi terendah yaitu 0,0000 dikarenakan hanya ditemukan satu spesies pada lokasi penelitian. Selain itu, syarat tumbuhnya pada $\mathrm{pH}$ 5,5-6,5 dan tidak terpapar matahari langsung atau tempat sejuk sementara pada lokasi penelitian spesies ini ditemukan di pesisir pantai yang terkena sinar matahari langsung.

\section{Indeks Keanekaragaman Shannon- Wienner}

Berdasarkan hasil penelitian yang dilakukan tumbuhan berbunga yang memiliki individu paling banyak yaitu Calophyllum inophyllum sebanyak 94 individu. Spesies ini ditemukan pada stasiun I, II dan III karena habitat yang sesuai dari tumbuhan tersebut. Sejalan dengan Syifalia dkk, (2017:4) bahwa, Calophyllum inophyllum dapat tumbuh dengan baik pada ketinggian 0-800 meter di atas permukaan laut yakni di hutan, rawa, pegunungan, daerah pantai yang kering, berpasir maupun yang digenangi air laut. Indeks keanekaragaman tumbuhan berbunga di Pantai Kapihak tergolong sedang dengan nilai $\mathrm{H}^{\prime}=2,851$ artinya persebaran spesies yang dilokasi penelitian tidak tersebar merata karena kondisi iklim dan tanah dipermukaan bumi sangat beragam. Selain itu, manusia berperan dalam keberadaan tumbuhan, baik yang sifatnya menjaga maupun merusak kehidupan tumbuhan agar dapat memenuhi kebutuhan hidupnya sehingga aktivitas manusia yang memanfaatkan tumbuhan berbunga secara terus-menerus yang tidak memperhatikan keberadaannya akan berdampak pula pada kelestarian tumbuhan berbunga.

\section{KESIMPULAN}

Pada penelitian ini ditemukan sebanyak 31 jenis tumbuhan berbunga yang termasuk kedalam 17 ordo, 22 famili dan 30 genus. Indeks nilai penting tinggi yaitu Jatropha gossypiifolia dengan nilai $1,348 \%$ sebanyak 56 individu. Indeks dominansi tergolong tinggi yaitu 1,038. Keanekaragaman Tumbuhan Berbunga Kelas Magnoliopsida di Pesisir Pantai Kapihak secara umum dapat dikategorikan sedang yaitu sebesar $\mathrm{H}=2,851$ yang artinya pesebaran spesies dilokasi penelitian tidak tersebar merata karena kondisi iklim dan tanah sangat beragam serta adanya aktivitas manusia yang memanfaatkan tumbuhan berbunga tanpa memperhatikan kelestariannya.

\section{DAFTAR PUSTAKA}

Alfaida., Suleman M.,\& Nurdin M. 2013. Jenis-jenis Tumbuhan Pantai di Desa 
Pelawa Baru Kecamatan Parigi Tengah Kabupaten Parigi Mautong dan Pemanfaatannya sebagai Buku Saku. JurusanIlmu Pendidikan Biologi Vol.1Hal 19-32.

BPS Kabupaten Sumba Timur .2016. diakses melalui https://kkp.go.id/SKPT/Sumba_Timur/ infografis-detail/2220-profil-umumkabupaten-sumba-timur.

Fern,

$$
\text { Ken. }
$$

tropical.theferns.info/viewtropical.php? $\mathrm{id}=$ Spigelia+anthelmia. Tropical Plants Database. Diakses 13 april 2021.

Gunawan, w., Basuni, S., Indrawan, A., Prasetyo, L., \& Soedjito, H. (2011). Analisis Komposisi Dan Struktur Vegetasi Terhadap Upaya Restorasi Kawan Hutan Taman Nasional Gunung Gede Pangrango. Jurnal Pengelolaan Sumberdaya alam dan Lingkungan. Vol (1). 2. Hal 93-105

Harianto. 2017. Respon Pertumbuhan Jarak Merah (Jatropha gossypifolia L.) Asal Kabupaten Nganjuk Akibat Cekaman Kekeringan. Hal 1-14

Handayani, T., \& Amanah, N. 2018. Keanekaragaman Jenis Tumbuhan Stata Herba Di Kawasan Gunung Tidar Kota Magelang Sebagai Belajar Biologi. Jurnal SENDIKA FKIP UAD, Vol 2. No. 1. Hal. 85

Huda, Muhammad. 2020. Keanekaragaman Tumbuhan Berbunga Di Kawasan Malesia.Jurnal Biologi Lingkungan, Industri, Kesehatan, Vol. 6. Hal 164

Hutasuhut, M. 2018. Keanekaragaman Tumbuhan Herba Di Cagar Alam Sibolangit. Jurnal Program Studi Biologi, Fakultas Sains Dan Teknologi, UIN Sumatera Utara Medan. Vol. 1 no. 2. Hal 69-77

Indrawan, Mohamad. 2012. Biologi Konservasi. Jakarta: Yayasan Pusat Obor Indonesia. Hal. 15.
Indriyanto. 2006.Ekologi Hutan. Jakarta: Penerbit PT Bumi Aksara. Hal 144145

Isnan, Wahyudi.,\& M, Nurhaedah. 2017. Ragam Manfaat Tanaman Kelor (Moringa oleifera Lamk.) Bagi Masyarakat. Balai Litbang Lingkungan Hidup dan Kehutanan Makassar. Hal 63-75

Kartasapoetra, A. G. 2006. Klimatologi Pengaruh Iklim terhadap Tanah dan Tanaman. Bumi Aksara: Jakarta.

Kundu, M., \& Schmidt, L. H. 2011. Schleicera oleosa (Lou.) Oken. Jurnal Seed Leaflet. No 153.

Kurniawati, N., \& Martono, E. 2015. Peran Tumbuhan Berbunga Sebagai Media Konservasi Artropoda Musuh Alami.Jurnal Perlindungan Taman Indonesia.19 (2), Hal 53-59

Lembaga Ilmu Pengetahuan Indonesia (LIPI). (2006). diaskes melalui lipi.go.id

Samedi.2015. Jurnal Hukum Lingkungan Indonesia. Konservasi Keanekaragaman Hayati di Indonesia. Vol.2 issue 02/Desember/2015:Indonesian Center for Environmental Law (ICEL): Jakarta Selatan (www.icel.or.id/jurnal). Hal 4 Magallón, S. 2009. Flowering plants (Magnoliophyta). The TimeTree of Life, Hal 161-165.

Mall, T. P., \& Tripathi, S. C. 2017. Kusum-A Multipurpose Plant From Katarniaghat Wildlife Sanctury Of Bahraich (Up) Indi-A Review. World Journal of Pharmaceutical Research,6. Hal 463477

Marlin., Yulian.,\&Gonggo, Bambang. 2010. Kultur Immature-embryo Cemara Laut (Casuarina equisetifolia) pada beberapa konsentrasi hara makro secara in vitro.Fakultas Pertanian: Bengkulu.Hal 1

Muanmar., Suleman, Samsurizal.,\& Nurdin, Musdalifah. $2017 . \quad$ Jenis-jenis Tumbuhan di Pesisir Pantai Desa Tibo 
Volume 3 Nomor 2 Desember 2021:47-54

dan Pemanfaatannya sebagai media pembelajaran.Jurusan Indonesia Pendidikan Biologi.Vol. 5.Hal 59

Nammi, s., Boini, M. K., Lodagala, S.D., \& Behara, R.B. 2003. The juice of fress leaves of Catharantus roseus Linn. Reduces blood glucose in normal and allonxan diabetic rabbits. $B M C$ Complementay and Alternative Medicine, Vol.3. Hal 147-156

Sada, J. T., \& Tanjung. 2010.Keragaman Tumbuhan Obat Tradiosional di Kampung Nansfori Distrik SupioriPapua.Jurnal Biologi Papua. Hal 39

Silalahi, M. 2017. Syzygium polyanthum (Wight) Walp.(Botani, Metabolit Sekunder dan Pamanfaatan).Jurnal Universitas Kristen Indonesia. vol 10, nomor 1. Hal 1-16

Syafitri, Igga. 2014. Identifikasi Struktur Anatomi Daun Tanaman Beringin (Ficus sp) serta Implementasinya Pada Pembelajaran IPA Biologi di SMP 1 Curup.Skripsi Universitas Bengkulu. Hal 10

Syifalia, L., \& Amarullah, K.A. 2017. Pemurnian Senyawa Trigliserida Dari
Minyak Nyamplung (Calophyllum inophyllum) Dengan Proses Continous Contercurrent Extraction. SripsiTK141581. Departemen Teknik Kimia. Fakultas Teknologi Industri. Institut Teknologi Sepuluh Nopember. Surabaya. Hal 4

Tjitrosoepomo, G. 2013. Taksonomi Tumbuhan Spermatophyta. Cetakan kesebelas. Yogyakarta: Gadjah Mada Universitas Press. Hal 90-381

Tuheteru, \& Mahfudz. 2012. Ekologi, Manfaat \& Rehabilitas Hutan Pantai Indonesia. (Manado: Balai Penelitian Kehutanan Manado).

Tutul, Ershad., Uddin, M.,\&Rahman, M. 2010. Angiospermic Flora of Runctia Sal Forest, Banglades, II. Magnoliopsida (Dicots).Bagladesh Journal of Plant Taxonomy. Hal 83

Wardhani, F \& Poedjirahajoe, E. 2020. Potensi Pemanfaatan Ipomea pescaprae (L.) R. Br. di Hutan Pantai Petanahan Kebumen. Jurnal Ilmu Kehutanan 14. Hal 145-153 